\title{
A Switch in the Neuromodulatory Effects of Dopamine in the Oval Bed Nucleus of the Stria Terminalis Associated with Cocaine Self-Administration in Rats
}

\author{
Michal Krawczyk, Robyn Sharma, Xenos Mason, ${ }^{\star}$ Julian DeBacker, ${ }^{\star}$ Andrea A. Jones, ${ }^{\star}$ and Éric C. Dumont \\ Department of Anesthesiology and Perioperative Medicine, Center for Neuroscience Studies, Queen's University, Kingston, Ontario K7L 3N6, Canada
}

Chronic exposure to drugs of abuse alters brain reward circuits and produces functional changes in the dopamine (DA) system. However, it is not known whether these changes are directly related to drug-driven behaviors or whether they simply are adaptive responses to long-term drug exposure. Here, we combined the rat model of cocaine self-administration with brain slice electrophysiology to identify drug-use related alterations in the neuromodulatory effects of DA in the oval bed nucleus of the stria terminalis (ovBST), a robust DA terminal field. Long-Evans rats self-administered cocaine intravenously $(0.75 \mathrm{mg} / \mathrm{kg} /$ injection $)$ for an average of $15 \mathrm{~d}$, on reward-lean or -rich schedules of reinforcement. Brain slice recordings conducted $20 \mathrm{~h}$ after the last self-administration session revealed a reversal of the neuromodulatory effect of DA on $\mathrm{GABA}_{\mathrm{A}}$-IPSCs. Specifically, the effect of DA switched from a D2-mediated decrease in drug-naive rats to a D1-receptor-mediated increase in $\mathrm{GABA}_{\mathrm{A}}$-IPSC in cocaine self-administering rats. Furthermore, the switch in DA modulation of $\mathrm{GABA}_{\mathrm{A}}$-IPSC remained after a $30 \mathrm{~d}$ withdrawal period. In contrast, this switch was not observed after the acquisition phase of cocaine self-administration, when rats received cocaine passively, or in rats maintaining sucrose self-administration. Therefore, our study reveals a reversal in the effects of DA on inhibitory transmission, from reduction to enhancement, in the ovBST of cocaine selfadministering rats. This change was unique to voluntary intake of cocaine and maintained after a withdrawal period, suggesting a mechanism underlying the maintenance of cocaine self-administration and perhaps craving during drug-free periods.

\section{Introduction}

Chronic and voluntary intake of drugs of abuse in animals has different neurological consequences than passive intake of the same substances or intake of natural rewards, such as sucrose (Dumont et al., 2005; Martin et al., 2006; Chen et al., 2008; You et al., 2008; Caillé et al., 2009; Kalant, 2010). For example, rats with a history of cocaine or nicotine self-administration demonstrate enhanced (in magnitude or duration) AMPA-mediated responses in several areas of the brain reward system, but these changes are not seen in rats self-administering a natural reward or when drug intake is passive (Dumont et al., 2005; Martin et al., 2006; Chen et al., 2008; You et al., 2008; Caillé et al., 2009; Kalant, 2010). Interestingly, it is currently unknown whether such neural changes specific to voluntary drug intake also occur in the brain dopamine (DA) system. DA is a potent modulator of both excitatory and inhibitory synaptic transmission, and the dopamine

Received Jan. 22, 2011; revised April 28, 2011; accepted April 29, 2011.

Author contributions: É.C.D. designed research; M.K., R.S., X.M., J.D., A.A.J., and É.C.D. performed research; M.K., R.S., X.M., J.D., A.A.J., and É.C.D. analyzed data; É.C.D. wrote the paper.

This project was supported by a Canadian Institutes of Health Research operating grant (MOP-79277), The J.P. Bickell Foundation, and Queen's University. We thank Cindy Chiang, Darya lanovskaia, Adam Schizkoske, and Robert laccino for technical support. We thank Drs. Mary C. Olmstead, Richard J. Beninger, Martin Paré, and Scott Hayton for providing feedback on the project and manuscript.

*X.M., J.D., and A.A.J. contributed equally to this work.

Correspondence should be addressed to Éric C. Dumont, Department of Anesthesiology and Perioperative Medicine, Center for Neuroscience Studies, Queen's University, 99 University Avenue, Kingston, Ontario K7L 3N6, Canada. E-mail: eric.dumont@queensu.ca.

DOI:10.1523/JNEUROSCI.0377-11.2011

Copyright $\odot 2011$ the authors $\quad 0270-6474 / 11 / 318928-08 \$ 15.00 / 0$ system is a preferential target for most drugs of abuse (Wise, 1996; Nicola et al., 2000). Passive in vivo (experimenter-administered) exposure to psychostimulants or opioids produces a variety of neuroadaptations in the effects of DA on synaptic transmission and neuronal activity (Higashi et al., 1989; Bonci and Williams, 1996; Beurrier and Malenka, 2002; Li and Kauer, 2004). However, these neuroadaptations have not been linked to drug self-administration behaviors, a necessary step to verify their involvement in addiction.

Here we sought to determine whether cocaine selfadministration would produce specific alterations in the neuromodulatory effects of DA in the oval subregion of the bed nucleus of the stria terminalis (ovBST), which is characterized by a high density of tyrosine hydroxylase-positive terminals, DARPP-32, and D2-like DA receptors (D2Rs) (Deutch et al., 1988; Gustafson and Greengard, 1990; Schalling et al., 1990; Phelix et al., 1992; Scibilia et al., 1992; Freedman and Cassell, 1994; Hasue and Shammah-Lagnado, 2002; Meloni et al., 2006; Krawczyk et al., 2011). We have previously shown that DA causes a D2Rdependent reduction of $\mathrm{GABA}_{\mathrm{A}}$-mediated inhibitory transmission in the ovBST of drug-naive rats (Krawczyk et al., 2011). Our study also demonstrated that the ovBST was largely devoid of D1-like DA receptors, an intriguing finding given that intraovBST microinjections of the D1R antagonist SCH-23390 reduce cocaine and ethanol self-administration in dependent rats (Epping-Jordan et al., 1998; Eiler et al., 2003). Therefore, we hypothesize that cocaine self-administration may be accompanied by functional alterations of DA receptors in the ovBST. 
To test this hypothesis, we combined cocaine selfadministration paradigms and brain slice electrophysiology in rats. We observed a D2R-to-D1R switch in the ovBST that resulted in a reversal (from decrease to enhancement) in the modulatory effects of DA on $\mathrm{GABA}_{\mathrm{A}}$-mediated synaptic transmission only in rats with a prolonged history of cocaine selfadministration. This switch in the neuromodulatory effects of DA was maintained after a $30 \mathrm{~d}$ drug-free period, suggesting that D1R-mediated increase in ovBST $\mathrm{GABA}_{\mathrm{A}}$-mediated synaptic transmission may contribute to the maintenance, craving, and perhaps, relapse to cocaine intake.

\section{Materials and Methods}

Subjects. One hundred thirty-one male Long-Evans rats (Charles River Laboratories) weighing 250-300 g were housed individually in a climatecontrolled colony room. The rats were maintained on a $12 \mathrm{~h}$ reversed light/dark cycle (9:00 A.M. lights off-9:00 P.M. lights on) with all behavioral testing occurring during the dark phase. The rats were allowed to acclimatize to surroundings for a minimum of $3 \mathrm{~d}$. Rat chow and water were provided ad libitum in the home cages and in the test chambers for the duration of the experimental sessions. All the experiments were conducted in accordance with the Canadian Council on Animal Care guidelines for use of animals in experiments and approved by the Queen's University Animal Care Committee.

Surgeries. Fifty-eight rats were weighed and anesthetized with isoflurane $(2-3 \%, 5 \mathrm{~L} / \mathrm{min})$. We used manufactured indwelling catheters for intrajugular cannulations (Model IVSA28, Camcath). The end of the tubing was inserted $32 \mathrm{~mm}$ into the right jugular vein, toward the right atria, and tied with 4-0 suturing silks. The rest of the tubing was fed subcutaneously to back-mounted 28 ga stainless steel cannulae. All incisions were closed with 4-0 absorbable suturing silk. Upon surgery completion and recovery from anesthesia, the rats were returned to the colony room. The rats received Anafen $(5 \mathrm{mg} / \mathrm{kg})$ injections, subcutaneously, for $3 \mathrm{~d}$ postoperatively and also received fruits to supplement normal chow diet during recovery. Intravenous cannulae were flushed daily with a sterile heparin-saline solution (20 IU heparin/ml) to prevent clots and conserve patency.

Acquisition of operant behaviors. Behavioral testing for sucrose or cocaine self-administration was conducted in operant chambers, each equipped with a house light, a response lever with cue light, and a food dispenser for sucrose pellet reinforcement (Med Associates). Rats were placed in the operant chambers for daily $4 \mathrm{~h}$ sessions. Rats learned sucrose- or cocaine-reinforced operant responding on a fixed ratio-1 (FR-1) schedule of reinforcement where each lever press illuminated the cue light and delivered the reward, either one sucrose pellet $(75 \mathrm{mg})$ or a cocaine- $\mathrm{HCl}$ infusion $(0.75 \mathrm{mg} / \mathrm{kg}$ in $0.12 \mathrm{ml}$ of sterile saline over $4 \mathrm{~s})$. Upon each reward delivery, the lever was retracted for $20 \mathrm{~s}$, during which the cue light remained illuminated; no additional responses could occur during this holding period. Training was considered acquired when the rats responded 25 times, in a titrated fashion (infusions or pellet delivery at regular time intervals), for 3 consecutive days.

Experimental groups. Rats were assigned to seven experimental groups: control $(n=45)$, sucrose $(n=28)$, acquisition $(n=10)$, cocainePR $(n=$ $32)$, yoked $(n=10)$, withdrawal $(n=3)$, and cocaineFR1 $(n=3)$. Rats in the control group were singly housed and age-matched to behaviorally trained rats. Rats in the acquisition group were killed for recordings $20 \mathrm{~h}$ following reaching criteria for acquisition of cocaine self-administration. These rats self-administered cocaine $(0.75 \mathrm{mg} / \mathrm{kg} /$ injection $)$ for $5 \pm 1 \mathrm{~d}$ on an FR-1 schedule. Rats in the sucrose and cocainePR groups graduated to a progressive ratio schedule of reinforcement (PR) in which lever pressing to obtain each subsequent reward increased according to the following equation: Response Ratio $=5 e^{\text {(injection number } \times 0.2)}-5$ (Richardson and Roberts, 1996). Rats in the cocainePR and sucrose groups remained on the PR schedule of reinforcement for $16 \pm 2$ and $19 \pm 3 \mathrm{~d}$, respectively (two-tailed Student's $t$ test on days on PR: $t_{(61)}=0.74, p=$ $0.75)$. At this chosen dose of cocaine $(0.75 \mathrm{mg} / \mathrm{kg} /$ injection $)$, rats from both the cocainePR $(71.2 \pm 6.5$ presses, $n=32)$ and sucrose $(53.5 \pm 7.9$ presses, $n=28$ ) groups reached a similar breaking point (two-tailed
Student's $t$ test on final ratio pressing: $\left.t_{(61)}=-1.71, p=0.09\right)$. A group of rats receiving cocaine passively (yoked) was included in the study to dissociate the neural mechanisms underlying drug-taking behavior from the neuroadaptations produced by chronic exposure to cocaine (Dumont et al., 2005). Accordingly, yoked rats received cocaine in exactly the same amount and frequency as their self-administering cocainePR counterparts. Levers were not available but reward delivery was also signaled by a $20 \mathrm{~s}$ cue light illumination. To determine potential neural long-term changes due to cocaine self-administration, rats assigned to the withdrawal group self-administered cocaine for $15 \mathrm{~d}$ under the PR schedule and were then withdrawn from training for $30 \mathrm{~d}$. Finally, rats assigned to the cocaineFR1 group were not graduated to the PR schedule but rather remained on an FR-1 schedule for $15 \mathrm{~d}$ following acquisition. We used this group to control for the switch from reward-rich (FR-1) to -lean (PR) schedules.

Brain slices preparation and electrophysiology. Approximately $20 \mathrm{~h}$ after the end of their last training session, rats were anesthetized with isoflurane and their brains rapidly removed. Coronal slices $(250 \mu \mathrm{m})$ containing the BST were prepared in a physiological solution containing (in mM) $126 \mathrm{NaCl}, 2.5 \mathrm{KCl}, 1.2 \mathrm{MgCl}_{2}, 6 \mathrm{CaCl}_{2}, 1.2 \mathrm{NaH}_{2} \mathrm{PO}_{4}, 25 \mathrm{NaHCO}_{3}$, and $11 \mathrm{D}$-glucose at $15^{\circ} \mathrm{C}$. Slices were incubated at $34^{\circ} \mathrm{C}$ for $60 \mathrm{~min}$ and transferred to a chamber that was constantly perfused $(3 \mathrm{ml} / \mathrm{min})$ with physiological solution maintained at $34^{\circ} \mathrm{C}$ and equilibrated with $95 \%$ $\mathrm{O}_{2} / 5 \% \mathrm{CO}_{2}$. Whole-cell voltage-clamp recordings were made using microelectrodes filled with a solution containing (in mM) $70 \mathrm{~K}^{+}$-gluconate, $80 \mathrm{KCl}, 1$ EGTA, 5 HEPES, 2 MgATP, 0.3 GTP, and 1 P-creatine. All recordings were restricted to the ovBST, and more precisely, to the dorsal half of the ovBST (Fig. 1A). The exact anteroposterior coordinates representing the brain slice used vary slightly between brain atlases $[-0.26$ $\mathrm{mm}$ and $-0.12 \mathrm{~mm}$ according to Swanson (2003) and Paxinos and Watson (2005), respectively] (Fig. $1 A$ ). In practice, we used the slices where the posterior part of the anterior commissure (ac) decussates but where the lateral extensions of the ac are still present. We thus recorded from a maximum of two slices per rat (four hemisections/rat) for consistent localization of the recordings. Recordings were restricted laterally to an imaginary vertical line that would run through the lateral ventricle. In addition, recordings were restricted to the area of the dorsolateral BST located dorsal to the halfway point between the tip of the lateral ventricle and the top of the ac (Fig. $1 \mathrm{~A}$ ). Postsynaptic currents were evoked by local fiber stimulation with tungsten bipolar electrodes while ovBST neurons were voltage clamped at $-70 \mathrm{mV}$. Stimulating electrodes were placed in the ovBST, $100-500 \mu \mathrm{m}$ lateral (IPSC) or dorsal (EPSC) from the recorded neurons (Fig. $1 A$ ), and paired electrical stimuli (10-100 $\mu \mathrm{A}, 0.1 \mathrm{~ms}$ duration, $20 \mathrm{~Hz}$ ) were applied at $0.1 \mathrm{~Hz}$. $\mathrm{GABA}_{\mathrm{A}}$-IPSC and AMPA-EPSC were pharmacologically isolated with DNQX $(50 \mu \mathrm{M})$ and picrotoxin $(100 \mu \mathrm{M})$, respectively. Recordings were made using a Multiclamp 700B amplifier and a Digidata 1440A (Molecular Devices Scientific). Data were acquired and analyzed with Axograph X running on Apple computers. $\mathrm{GABA}_{\mathrm{A}}$-IPSCs were measured in all seven groups of rats, whereas AMPA-EPSCs were only investigated in control, sucrose, and cocainePR rats. Since pilot studies showed no effect of Cocaine selfadministration on DA or NA modulation of AMPA-EPSC, we reasoned that results from yoked, withdrawal, acquisition, and cocaineFR1 groups would be of limited interest.

Drugs. Stock solution of DA (10 mM), NA (10 mm), quinpirole (1 mM), and SCH-23390 (10 mM) were prepared in double-distilled water. Stock solution of DNQX (100 mM), SKF-81297 (1 mM), sulpiride (1 mM), and yohimbine $(1 \mathrm{mM})$, were prepared in DMSO $(100 \%)$. Each drug was further dissolved in the physiological solutions at the desired concentration and the final DMSO concentration never exceeded $0.1 \%$. Cocaine$\mathrm{HCl}$ was dissolved at $2.5 \mathrm{mg} / \mathrm{ml}$ in sterile saline and $\mathrm{pH}$ was adjusted to 7.3 with $\mathrm{NaOH}$. All drugs were obtained from Sigma-Aldrich or Tocris Biosciences except cocaine- $\mathrm{HCl}$ (Medisca).

Statistical analysis. We measured drug-induced change in postsynaptic current (PSC) peak amplitude from baseline in percentage ([(Peak amplitude $_{\text {drug }}-$ Peak amplitude $\left._{\text {baseline }}\right) /$ Peak amplitude baseline $\left.] \times 100\right)$ 5-10 min after bath application of the drugs. We assessed drug effects using two-tailed $t$ tests with hypothesized values of $0\left[H_{0}: \Delta \mathrm{GABA}_{\mathrm{A}}\right.$-IPSC $(\%)=0$ ]. We minimized type I error with a Bonferroni-adjusted $\alpha$ level 
( $\alpha=0.05 /$ number of $t$ tests). We calculated paired-pulse ratios (PPRs) by dividing the second (S2) by the first (S1) peak amplitude that we normalized to baseline. We calculated peak amplitudes for S1 and S2 from a baseline value measured immediately before the stimulus artifacts. We assessed drug effects on PPR using twotailed $t$ tests with hypothesized values of $1\left[H_{0}\right.$ : $\Delta \mathrm{PPR}($ Normalized $)=1]$. We minimized type I error with a Bonferroni-adjusted $\alpha$ level ( $\alpha=$ $0.05 /$ number of $t$ tests). We used multiple $t$ tests because we only measured the full dose-response effect in control, sucrose, and cocainePR rats. We analyzed the coefficient of variation (CV) by plotting $r\left[\left(1 / \mathrm{CV}_{\text {drug }}^{2}\right) /\left(1 / \mathrm{CV}_{\text {baseline }}^{2}\right)\right]$ against $\pi$ (Peak amplitude $_{\text {drug }}$ /Peak amplitude baseline $_{\text {(n) }}$ and computed bivariate linear fits of $r$ by $\pi$ (Faber and Korn, 1991). We used one-way ANOVAs to compare multiple means and conducted appropriate statistical tests for multiple comparisons (indicated in Results and figures) when ANOVAs deemed significance. All statistical analyses were done with JMP 9.0 (SAS Institute).

\section{Results}

Measures of synaptic transmission in the rat ovBST (Fig. 1)

Local fiber electrical stimulation reproducibly evoked GABA $_{\mathrm{A}}$-IPSCs and AMPA-EPSCs (Fig. 1). To determine the probability of neurotransmitter release $\left(P_{\mathrm{r}}\right)$ across the different groups, we measured and compared the paired-pulse ratio $\left(\mathrm{PPR}_{50 \mathrm{~ms}}\right)$ of evoked $\mathrm{GABA}_{\mathrm{A}}$-IPSC and AMPA-EPSC (Fig. 1C1). Evoked $\mathrm{GABA}_{\mathrm{A}}$-IPSC predominantly displayed a slight and similar depression (PPD) in all seven groups of rats $\left(F_{(6,178)}=0.79, p=\right.$ $0.58)$, a feature characteristic of a population of synapses with high Pr. In contrast, the $\mathrm{PPR}_{50 \mathrm{~ms}}$ of evoked AMPA-EPSC resulted in paired-pulse facilitation (PPF) in control, sucrose, and cocainePR groups $\left(F_{(2,140)}=0.71, p=0.49\right)$. AMPA-EPSC from acquisition and yoked groups was not studied, because maintenance of cocaine self-administration did not produce any measurable changes at excitatory synapses (see Fig. 5). Altogether, PPR analyses revealed no treatment effects on the probability of neurotransmitter release in the ovBST.

\section{Neuromodulatory effects of DA on inhibitory synaptic transmission}

(Fig. 2)

As previously reported (Krawczyk et al., 2011), bath application of DA $(0.1-30 \mu \mathrm{M})$ decreased the amplitude of evoked $\mathrm{GABA}_{\mathrm{A}^{-}}$ IPSC in a reversible and dose-dependent manner in the ovBST of control rats (Fig. 2A1,B1). At DA concentrations that decreased $\mathrm{GABA}_{\mathrm{A}}$-IPSC, we observed statistically significant increases in $\mathrm{PPR}_{50 \mathrm{~ms}}$, suggesting that DA acts presynaptically (Fig. 2B2) (Zucker, 1989). Confirming the PPR, a CV analysis revealed a significant positive correlation, further supporting the idea that DA acts presynaptically (Fig. 2C1) (Faber and Korn, 1991). At 1 $\mu \mathrm{M}$, DA produced a similar presynaptic reduction in $\mathrm{GABA}_{\mathrm{A}}-$ IPSC in the ovBST of sucrose, acquisition, and yoked rats (Fig. 2).
In contrast, in cocainePR rats, exposure to $1 \mu \mathrm{M}$ DA caused a significant presynaptic increase in the amplitude of $\mathrm{GABA}_{\mathrm{A}}$-IPSC (Fig. 2A3, B, C3). This effect was dose specific, however, because $10 \mu \mathrm{M}$ DA did not produce any effect in cocainePR rats, and 30 $\mu \mathrm{M}$ DA produced a reduction in $\mathrm{GABA}_{\mathrm{A}}$-IPSC amplitude in cocainePR rats, although significantly smaller than in the control and sucrose groups (Fig. 2B1). At concentrations lower than 0.1 $\mu \mathrm{M}, \mathrm{DA}$ did not change $\mathrm{GABA}_{\mathrm{A}}$-IPSC amplitude in control, sucrose, or cocainePR rats (data not shown). We further confirmed that the switch in the neuromodulatory effects of DA $(1 \mu \mathrm{M})$ on $\mathrm{GABA}_{\mathrm{A}}$-IPSC also occurred in rats self-administering cocaine on a reward-rich schedule of reinforcement. Accordingly, in rats that remained on an FR-1 schedule (cocaineFR1), DA $1 \mu \mathrm{M}$ presynaptically increased the amplitude of $\mathrm{GABA}_{\mathrm{A}}$-IPSC $(2 \mathrm{B1}, \mathrm{B2})$. We also investigated whether the effects of DA on GABA AIPSC would remain altered during withdrawal and saw that indeed, DA enhanced the amplitude of $\mathrm{GABA}_{\mathrm{A}}$-IPSC after a $30 \mathrm{~d}$ withdrawal period (Fig. 2 B1,B2). 

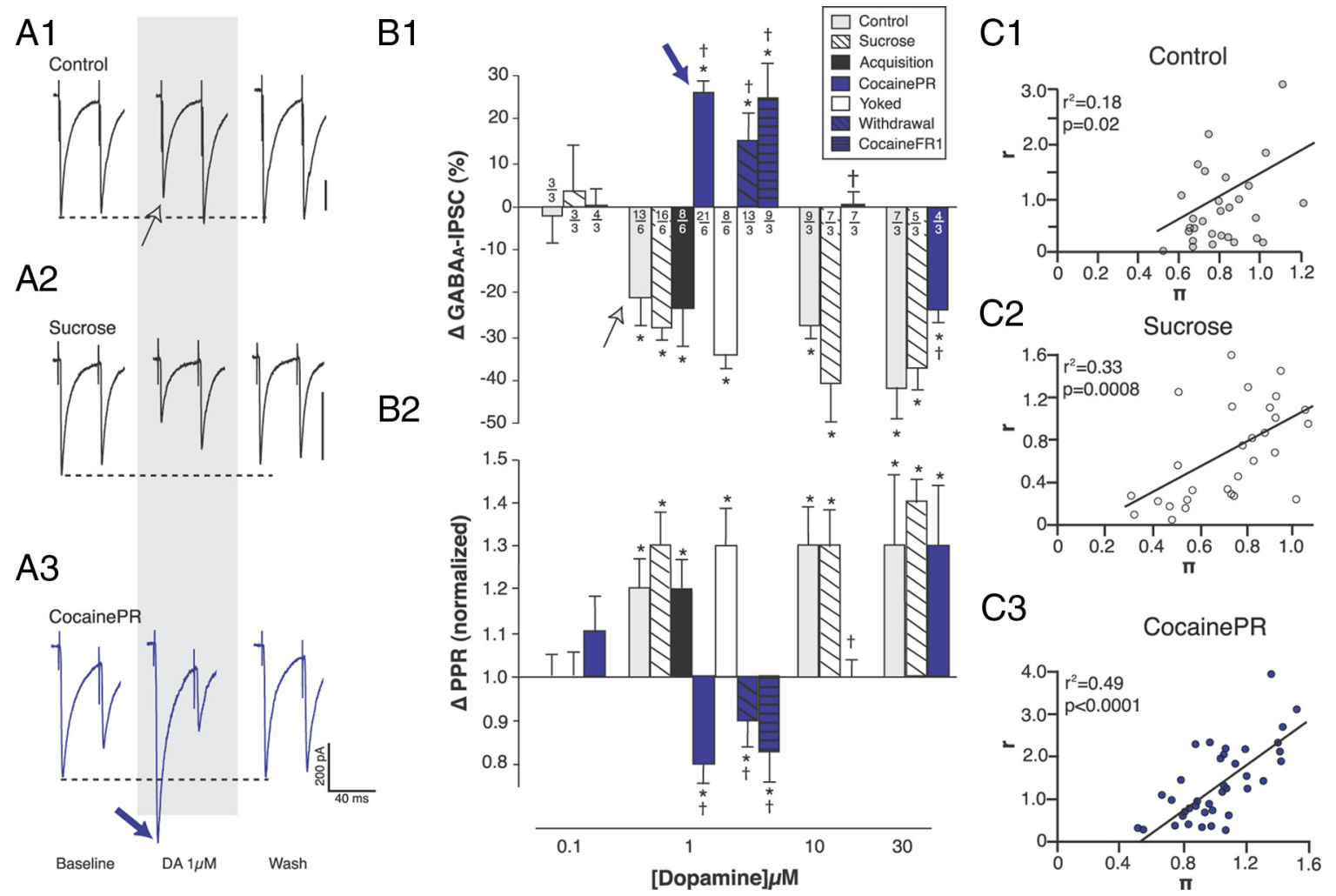

Figure 2. Effects of DA on GABA - IPSC. $A$, Representative traces showing the effects of bath-applied DA on the amplitude of evoked GABA $A_{A}-$ IPSC in brain slices from control (A1), sucrose ( $\boldsymbol{A 2}$ ), and cocainePR (A3) rats. $\boldsymbol{B}$, Bar graphs summarizing the effect of DA on the amplitude (B1) and PPR (B2) of evoked GABA - -IPSC. *Significantly different from 0 (amplitude) or 1 (PPR); two-tailed Student's $t$ tests, $p<0.001$. 'Significantly different from control, sucrose, acquisition, and yoked; one-way ANOVA, $p<0.01$. Numbers indicate the number of neurons (above) and rats (below), respectively. C, Dot plots summarizing $(V$ analyses of the effects of DA (0.1-30 $\mu \mathrm{M})$ on evoked GABA $A_{A}^{-I P S C}$ in brain slices from control (C1), sucrose (C2), and cocainePR (C3) rats. Dot plots show $r$ $\left[\left(1 /\left(V_{\text {drug }}^{2}\right) /\left(1 /\left(V_{\text {baseline }}^{2}\right)\right]\right.\right.$ as a function of $\pi$ (Peak amplitude drug $_{\text {Peak amplitude }} /$ baseline $\left._{\text {e }}\right)$.

\section{DA receptors (Figs. 3,4 )}

In the control, sucrose, acquisition and yoked groups, the effect of DA on $\mathrm{GABA}_{\mathrm{A}}$-IPSC was mediated by D2-like DA receptors (D2R). Consistent with this, the D2R agonist quinpirole $(1 \mu \mathrm{M})$ mimicked the effects of DA on GABA - -IPSC and the D2R antagonist sulpiride $(10 \mu \mathrm{M})$ blocked DA-induced reduction in $\mathrm{GABA}_{\mathrm{A}}$-IPSC amplitude in these groups of rats (Fig. 3). PPR analyses suggest that $\mathrm{D} 2 \mathrm{R}$ are located presynaptically (Fig. $3 \mathrm{~B} 2$ ). In contrast, quinpirole had almost no effect on $\mathrm{GABA}_{\mathrm{A}}$-IPSC in cocainePR, withdrawal, and cocaineFR1 rats (Fig. $3 B$ ). In slices from the cocainePR group, the D1R agonist SKF-81297 (1 $\mu \mathrm{M})$ increased the amplitude of $\mathrm{GABA}_{\mathrm{A}}$-IPSC (Fig. 4). Noticeably, the effect of SKF-81297 on GABA $A_{A}$-IPSC amplitude in the cocainePR group was similar to the effect of $1 \mu \mathrm{M}$ DA 5-10 min after bath application, but it did not plateau until $\sim 30 \mathrm{~min}$ after application (data not shown). These results suggest a persistent D1Rmediated response specific to cocainePR rats. Finally, the D1R antagonist SCH-23390 $(10 \mu \mathrm{M})$ completely abolished the effect of DA $(1 \mu \mathrm{M})$ in cocainePR rats, but had no effect in the control group (Fig. $4 B, C$ ).

\section{Neuromodulatory effects of DA on excitatory synaptic transmission (Fig. 5)}

As we previously reported (Krawczyk et al., 2011), bath application of DA $(0.1-30 \mu \mathrm{M})$, reversibly and dose-dependently decreased the amplitude of evoked AMPA-EPSC in the ovBST of control rats (Fig. 5A1,B1). $\mathrm{PPR}_{50 \mathrm{~ms}}$ and $\mathrm{CV}$ analyses suggest that this is a presynaptic effect (Fig. 5B2,C) (Zucker, 1989). However, DA was 10 times less potent at reducing the amplitude of AMPA-
EPSC than at reducing that of $\mathrm{GABA}_{\mathrm{A}}$-IPSC (Figs. 2 $\mathrm{B1}, 5 \mathrm{B1}$ ) (Krawczyk et al., 2011). Furthermore, SKF-81297 and quinpirole, D1R and D2R agonists, respectively, did not affect AMPA-EPSC amplitude in control rats (Table 1). In contrast, the $\alpha 2$ adrenergic receptor $(\alpha 2 \mathrm{R})$ antagonist yohimbine $(5 \mu \mathrm{M})$ completely blocked the effect of DA on AMPA-EPSC (Fig. 5B1) (Krawczyk et al., 2011), and noradrenaline (NA) was three times more potent than DA at presynaptically reducing AMPA-EPSC (Fig. 5B1,E1). The effects of DA, NA, and DA agonists on AMPAEPSC were similar in control, sucrose, and cocainePR rats (Fig. 5, Table 1). These data suggest that the effect of DA on excitatory synaptic transmission is mediated by $\alpha 2 \mathrm{R}$ (Zhang et al., 1999; Cornil et al., 2002; Zhang and Ordway, 2003; Cornil and Ball, 2008; Guiard et al., 2008; Krawczyk et al., 2011) and that $\alpha 2$ Rs are not functionally altered with operant responding for either a pharmacological or natural reward.

\section{Discussion}

DA decreases $\mathrm{GABA}_{\mathrm{A}}$-mediated inhibitory transmission in the rat ovBST by activating presynaptic D2R (Krawczyk et al., 2011; this study). Here we show, however, that DA causes a D1Rmediated increase in $\mathrm{GABA}_{\mathrm{A}}$ inhibitory transmission in the rat ovBST during maintenance of cocaine self-administration, a change that remained after a $30 \mathrm{~d}$ drug-free period. Thus, the effect of DA on $\mathrm{GABA}_{\mathrm{A}}$-mediated inhibitory transmission in the ovBST is reversed and the DA receptor subtype is altered in the rat ovBST during maintenance of cocaine self-administration. This switch is specific for maintenance of cocaine self-administration, and is not observed after acquisition of cocaine self-administration, 
during maintenance of sucrose selfadministration, or when cocaine delivery is not contingent upon lever pressing. We conclude that this switch in the neuromodulatory effect of DA in the ovBST is likely a feature of drug-driven behaviors since it did not occur in rats selfadministering sucrose. This observation contrasted slightly with our previous report demonstrating that operant responding for sucrose increases AMPA-mediated currents, albeit by a lesser magnitude than cocaine and in the ventrolateral BST (Dumont et al., 2005). Thus, this novel result significantly expands our understanding of the neural circuits and mechanisms involved in chronic drug intake in a preclinical setting.

\section{Dysfunctional D2R in cocaine self-administering rats}

The switch from a D2R-dependent reduction of $\mathrm{GABA}_{\mathrm{A}}$-mediated inhibitory transmission to a D1R-mediated increase in $\mathrm{GABA}_{\mathrm{A}}$ inhibitory transmission was associated with decreased $\mathrm{D} 2 \mathrm{R}$ and de novo D1R activity. Decreased D2R function correlates with increased vulnerability to the reinforcing and addictive properties of cocaine in animal models and humans (Volkow et al., 1990, 1993; Morgan et al., 2002; Nader et al., 2002, 2006; Dalley et al., 2007). Thus, the present study extends this observation to another DA terminal field, the ovBST, and to the experimental context of maintenance of, and protracted withdrawal from, cocaine self-administration. This D2R dysfunction associated with drug abuse may be linked to fewer receptors, uncoupling of receptor-effector pathways, or other mechanisms of desensitization (Namkung and Sibley, 2004; Namkung et al., 2009). In the current experimental model, D2R dysfunction was rescued by adenylate cyclase (AC) activation with bath application of forskolin (data not shown). This suggests that cocaine self-administration decreases the D2R-AC/PKA response in the ovBST, and that this effect is pharmacologically reversible, in vitro. This model may be of particular interest because D2R dysfunction and decrease in D2R binding sites in rhesus monkeys (Moore et al., 1998; Nader et al., 2002) are specifically associated with cocaine self-administration. We showed that D2R was not restored following a $30 \mathrm{~d}$ withdrawal period. Future studies could investigate whether D2R hypofunction remains after longer detoxification periods. Furthermore, whether interventions aimed at stimulating D2R function in the reward circuit increase the capacity for abstinence from addictive drugs could also be tested.

\section{De novo $\mathrm{D} 1 \mathrm{R}$ function in cocaine self-administering rats}

D2R function in the ovBST was intact during acquisition of cocaine self-administration, suggesting that D2R dysfunction may play a role in the transition to compulsive drug use (DerocheGamonet et al., 2004; Vanderschuren and Everitt, 2004; Johnson and Kenny, 2010). De novo D1R function, which was specifically observed in the ovBST during maintenance of cocaine selfadministration, could also play a role in the transition to compulsive drug use. In rhesus monkeys, cocaine self-administration
B1

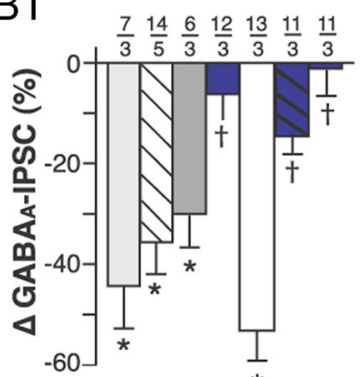

C

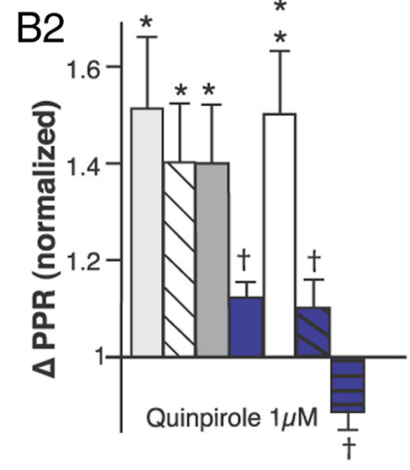$$
\uparrow
$$

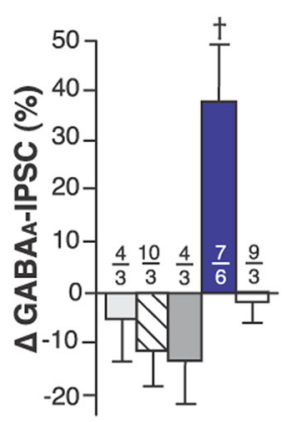

$\mathrm{DA} 1 \mu \mathrm{M}+$ Sulpi $10 \mu \mathrm{M}$

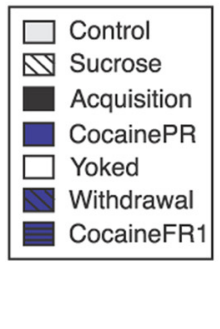$$
\text { . }
$$

Figure 3. D2R-mediated effects of DA on $G A B A_{A}-I P S C$. $A$, Representative traces showing the effects of the D2R agonist quinpirole $(1 \mu \mathrm{m})$ on evoked $\mathrm{GABA}_{A}-\mathrm{IPSC}$ in brain slices from control (A1) and cocainePR $(\boldsymbol{A} 2)$ rats. $\boldsymbol{B}$, Bar graph summarizing the effect of (PPR); two-tailed Student's $t$ tests, $p<0.001$. ' Significantly different from control, sucrose, acquisition, and yoked; one-way ANOVA, $p<0.05$. Numbers indicate the number of neurons (above) and rats (below), respectively.
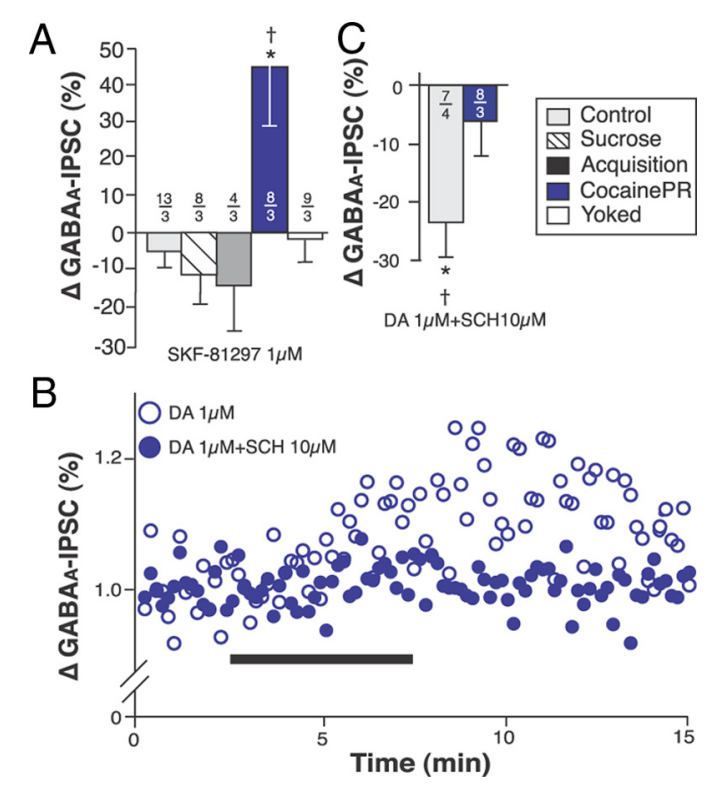

Figure 4. D1R-mediated effects of DA on $\mathrm{GABA}_{A}-\mathrm{IPSC} . A$, Bargraph summarizing the effects of the D1R agonist SKF-81297 on the amplitude of GABA $A_{A}-$ IPSC. B, Dot plot (representative experiment) showing the effect of DA on the amplitude of GABA-IPSC as a function of time in the absence (open circles) or presence (closed circles) of the D1RantagonistSCH-23390 $(10 \mu \mathrm{M})$. Black bar indicates bath application of DA. C, Bar chart summarizing the effect of DA $(1 \mu \mathrm{m})$ on the amplitude of evoked $\mathrm{GABA}_{A}$-IPSC in the presence of the D1R antagonist SCH-23390 $(10 \mu \mathrm{M})$. ${ }^{*}$ Significantly different from 0 (amplitude) or 1 (PPR); two-tailed Student's t tests, $p<0.001$. 'Significantly different from all other groups; one-way ANOVA, $p<0.05$. Numbers indicate the number of neurons (above) and rats (below), respectively.

is associated with an increase in D1R binding activity in the shell of the nucleus accumbens, an extended amygdala structure closely related and robustly connected to the ovBST (Dong et al., 

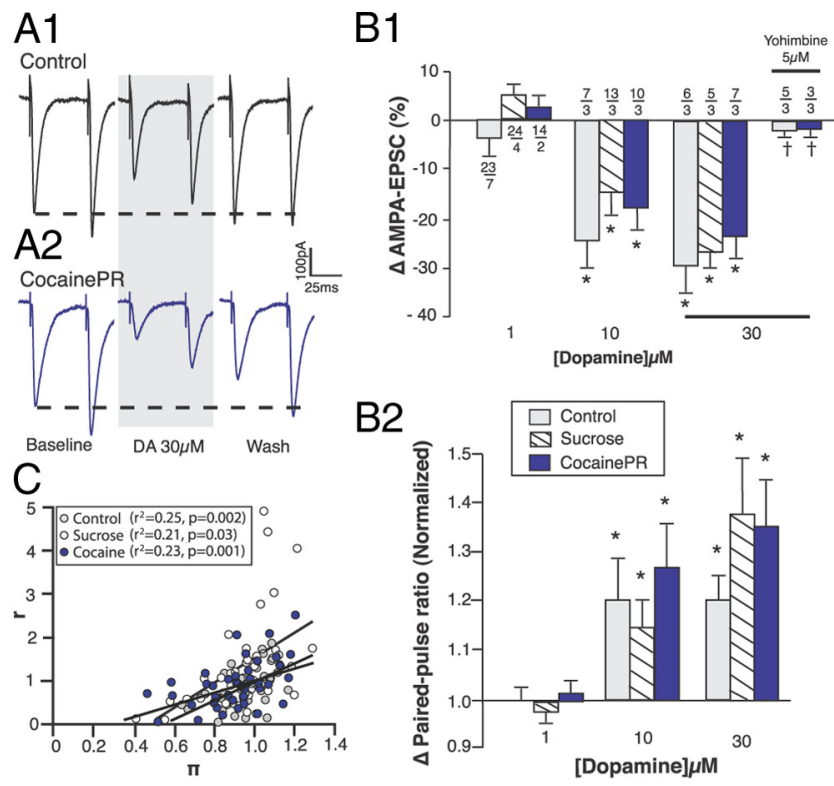

D1

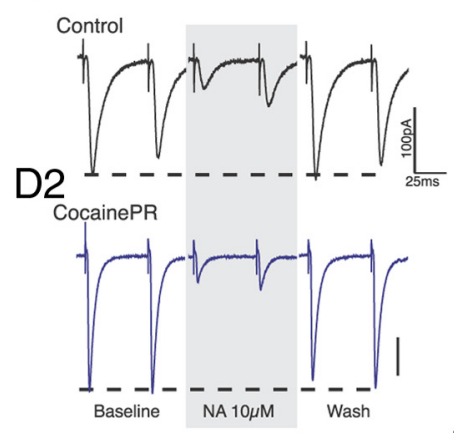

F

E1

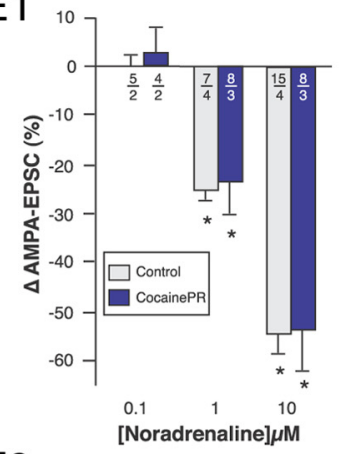

E2
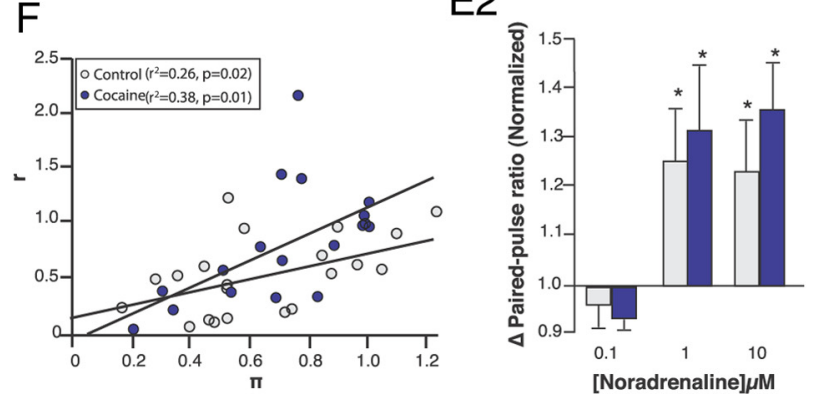

Figure 5. Effect of DA on AMPA-EPSC. $A$, Representative traces showing the effect of DA on evoked AMPA-EPSC in the ovBST of control ( $\boldsymbol{A} \boldsymbol{1})$ and cocainePR ( $\boldsymbol{A} 2)$ rats. $\boldsymbol{B}$, Bar graphs summarizing the effect of DA on the change in amplitude (B1) and PPR (B2) of evoked AMPA-EPSC. *Significantly different from 0 (amplitude) or 1 (PPR); two-tailed Student'st tests, $p<0.005$.C, Dot plot showing CV analyses of the effect of DA (1-30 $\mu$ M) on evoked AMPA-EPSC. D, Representative traces showing the effect of NA on evoked AMPA-EPSC in the ovBST of control (D1) and cocainePR (D2) rats. $\boldsymbol{E}$, Bar graphs summarizing the effects of NA on the change in amplitude (E1) and paired-pulse ratios (E2) of evoked AMPA-EPSC. *Significantly different from 0 (amplitude) or 1 (PPR); two-tailed Student's $t$ tests, $p<0.001$. F, Dot plot showing $C V$ analyses of the effect of NA (0.1-10 $\mu \mathrm{m})$ on evoked AMPA-EPSC in both control and cocainePR groups.

2001b; Nader et al., 2002). Furthermore, virtually no immunostaining or functional D1R could be detected in the ovBST of drug-naive rats (Krawczyk et al., 2011). These results are consistent with the idea that cocaine self-administration promotes the expression of the D1R gene or receptor trafficking to the membrane surface. This could be facilitated by a direct protein-protein interaction between D1R and NMDA receptors, a phenomenon
Table 1. Effects of DA receptor agonists on the amplitude of evoked AMPA-EPSCs in the ovBST

\begin{tabular}{llllll}
\hline & \multicolumn{3}{l}{ SKF-81297 } & \multicolumn{3}{l}{ Quinpirole } \\
\cline { 2 - 3 } \cline { 5 - 6 } & $0.1 \mu \mathrm{M}$ & $1 \mu \mathrm{M}$ & & $0.1 \mu \mathrm{M}$ & $1 \mu \mathrm{M}$ \\
\hline Control & $-6.0 \pm 2.3(9)$ & $-6.5 \pm 4.3(6)$ & & $-1.5 \pm 2.5(7)$ & $-0.6 \pm 2.2(8)$ \\
Sucrose & $-1.2 \pm 3.2(14)$ & $-2.8 \pm 3.8(14)$ & & $-1.6 \pm 2.1(13)$ & $-8.9 \pm 3.9(9)$ \\
CocainePR & $-2.9 \pm 2.8(12)$ & $-2.5 \pm 2.0(13)$ & $-5.6 \pm 2.8(15)$ & $-0.9 \pm 4.3(8)$ \\
\hline
\end{tabular}

Values are $\triangle \mathrm{AMPA}-\mathrm{EPSC}$ (percentage); $n$ values are given in parentheses.

previously observed in heterologous cellular models and dissociated hippocampal neurons (Pei et al., 2004). D1R hypersensitivity has also been reported in animal models of DA depletion. For example, D1R hypersensitivity involves a switch in intracellular signaling pathways in dopamine-depleted striatum (Gerfen et al., 2002). Additional studies are required to investigate whether any of these mechanisms are involved in the maintenance of cocaine self-administration, relapse to cocaine intake, or incubation of cocaine craving.

\section{Consequence of DA receptor switch on ovBST function}

We observed reduced D2R and increased D1R activity (at GABA synapses) in rats maintaining cocaine self-administration, which may consequently increase GABAergic tone in the ovBST. This DA-mediated increase in inhibitory tone in the ovBST should result in a net decrease in output of ovBST projection neurons. The ovBST is exclusively populated with GABA neurons that coexpress CRF, neurotensin, somatostatin, enkephalin, and/or dynorphin (Ju et al., 1989; Moga et al., 1989; Veinante et al., 1997; Day et al., 1999) and should exert an inhibitory effect on afferent targets. The ovBST targets includes brain areas within (e.g., fusiform BST) and outside the BST (e.g., nucleus accumbens shell, lateral hypothalamus, retrorubral field, parabrachial nucleus, central amygdala) (Dong et al., 2001a). The current study did not examine the consequences of DA-mediated increase in $\mathrm{GABA}_{\mathrm{A}}$ mediated transmission on the ovBST neural network. However, a previous study showed that microinjection of a $\mathrm{GABA}_{\mathrm{A}}$ receptor antagonist into the dorsolateral BST reduced GABAergic tone and ethanol self-administration in rats (Hyytiä and Koob, 1995). Because dorsolateral BST D1R blockade also reduced cocaine self-administration (Epping-Jordan et al., 1998), it seems reasonable to suggest that D1-mediated increase in ovBST GABAergic tone contributes to drug-driven operant behaviors. Consistent with the hypothesis that DA may decrease ovBST output in cocaine-dependent rats and promote motivated behaviors, systemic injection of anorexinergic agents triggers the expression of the protein Fos (an indicator of neuronal activation) in the ovBST (Bonaz et al., 1993; Li et al., 1994; Li and Rowland, 1995; Rowland et al., 1996). Together, this evidence suggests that ovBST neuronal activity inversely correlates with motivated behaviors.

\section{DA modulation of excitatory synaptic transmission in the ovBST}

DA reduces excitatory synaptic transmission mediated by AMPA ionotropic receptors in the ovBST by cross-activating presynaptic $\alpha 2 \mathrm{R}$, a mechanism that is not altered by cocaine selfadministration [see Fig. 5 and Krawczyk et al. (2011)]. It is worth mentioning that in rats chronically exposed to psychostimulants (in an experimenter-controlled manner), there are increases in D1R-mediated modulation of excitatory transmission in the nucleus accumbens (Higashi et al., 1989; Beurrier and Malenka, 2002; Li and Kauer, 2004). Although an increase in D1R function 
was also observed in the ovBST of cocainePR rats in our study, these receptors seemed restricted to inhibitory transmission, showing a remarkable distinction with ventral striatum areas. Importantly, DA (at concentrations 10 times higher than required to modulate inhibitory transmission) may still modulate excitatory synaptic transmission in the ovBST. Cocaine may promote this mechanism by producing large DA transients in the BST (Carboni et al., 2000). The behavioral significance of this potential effect of DA on ovBST AMPA currents is, however, unknown and may be difficult to evaluate experimentally.

\section{Neural mechanisms underlying voluntary cocaine intake}

The rodent model of stimulant self-administration has been a relatively good predictor of human substance abuse behavior (Deroche-Gamonet et al., 2004; Vanderschuren and Everitt, 2004; Panlilio, 2010). Our previous brain slice patch-clamp studies using this model demonstrated that alteration in synaptic plasticity of excitatory synapses in the ventrolateral portion of the BST correlated with cocaine self-administration, but not with passive (or noncontingent) cocaine intake (Dumont et al., 2005). Similar results reported in the nucleus accumbens suggest that the neurological mechanisms associated with voluntary and passive exposure to drugs of abuse are fundamentally different, and that it is critical to understand and differentiate these mechanisms to distinguish addictive behavior from adaptation to chronic drug exposure (Martin et al., 2006; Chen et al., 2008).

\section{Role of ovBST D1R in drug-driven operant behaviors}

Previous studies showed that intra-ovBST D1R blockade reduces cocaine- and ethanol- but not sucrose-driven operant behaviors in rats (Epping-Jordan et al., 1998; Eiler et al., 2003). We previously demonstrated the absence of D1R immunostaining and function in the ovBST of drug-naive rats, a result that contrasts with behavioral studies. Here we reconcile the physiological, anatomical, and behavioral data by showing de novo D1R function in cocaine-dependent rats. Altogether, our study adds to growing evidence supporting a role for the dorsal BST in drug-taking behaviors and relapse to drug seeking after drug-free periods (Epping-Jordan et al., 1998; Walker et al., 2000; Erb et al., 2001; Leri et al., 2002; Eiler et al., 2003).

In summary, we identified a switch in DA regulation of $\mathrm{GABA}_{\mathrm{A}}$-IPSC in the ovBST that was specifically associated with cocaine self-administration and remained after a $30 \mathrm{~d}$ drug-free period. This drug and behavior-induced switch was associated with dysfunctional presynaptic $\mathrm{D} 2 \mathrm{R}$ signaling as well as de novo D1R responses. Furthermore, the switch was not observed with passive drug exposure or self-administration of a natural reward, revealing a potential target for the management of substance abuse. Although D1R antagonists are associated with adverse effects that preclude their use in drug addiction therapy, identifying and characterizing D1R downstream signaling pathways may reveal interesting therapeutic alternatives (Nann-Vernotica et al., 2001).

\section{References}

Beurrier C, Malenka RC (2002) Enhanced inhibition of synaptic transmission by dopamine in the nucleus accumbens during behavioral sensitization to cocaine. J Neurosci 22:5817-5822.

Bonaz B, De Giorgio R, Taché Y (1993) Peripheral bombesin induces c-fos protein in the rat brain. Brain Res 600:353-357.

Bonci A, Williams JT (1996) A common mechanism mediates long-term changes in synaptic transmission after chronic cocaine and morphine. Neuron 16:631-639.

Caillé S, Guillem K, Cador M, Manzoni O, Georges F (2009) Voluntary nicotine consumption triggers in vivo potentiation of cortical excitatory drives to midbrain dopaminergic neurons. J Neurosci 29:10410-10415.

Carboni E, Silvagni A, Rolando MT, Di Chiara G (2000) Stimulation of in vivo dopamine transmission in the bed nucleus of stria terminalis by reinforcing drugs. J Neurosci 20:RC102.

Chen BT, Bowers MS, Martin M, Hopf FW, Guillory AM, Carelli RM, Chou JK, Bonci A (2008) Cocaine but not natural reward self-administration nor passive cocaine infusion produces persistent LTP in the VTA. Neuron 59:288-297.

Cornil CA, Ball GF (2008) Interplay among catecholamine systems: dopamine binds to alpha2-adrenergic receptors in birds and mammals. J Comp Neurol 511:610-627.

Cornil CA, Balthazart J, Motte P, Massotte L, Seutin V (2002) Dopamine activates noradrenergic receptors in the preoptic area. J Neurosci 22:9320-9330.

Dalley JW, Fryer TD, Brichard L, Robinson ES, Theobald DE, Lääne K, Peña Y, Murphy ER, Shah Y, Probst K, Abakumova I, Aigbirhio FI, Richards HK, Hong Y, Baron JC, Everitt BJ, Robbins TW (2007) Nucleus accumbens D2/3 receptors predict trait impulsivity and cocaine reinforcement. Science 315:1267-1270.

Day HE, Curran EJ, Watson SJ Jr, Akil H (1999) Distinct neurochemical populations in the rat central nucleus of the amygdala and bed nucleus of the stria terminalis: evidence for their selective activation by interleukin1beta. J Comp Neurol 413:113-128.

Deroche-Gamonet V, Belin D, Piazza PV (2004) Evidence for addiction-like behavior in the rat. Science 305:1014-1017.

Deutch AY, Goldstein M, Baldino F Jr, Roth RH (1988) Telencephalic projections of the A8 dopamine cell group. Ann N Y Acad Sci 537:27-50.

Dong HW, Petrovich GD, Swanson LW (2001a) Topography of projections from amygdala to bed nuclei of the stria terminalis. Brain Res Brain Res Rev 38:192-246.

Dong HW, Petrovich GD, Watts AG, Swanson LW (2001b) Basic organization of projections from the oval and fusiform nuclei of the bed nuclei of the stria terminalis in adult rat brain. J Comp Neurol 436:430-455.

Dumont EC, Mark GP, Mader S, Williams JT (2005) Self-administration enhances excitatory synaptic transmission in the bed nucleus of the stria terminalis. Nat Neurosci 8:413-414.

Eiler WJ 2nd, Seyoum R, Foster KL, Mailey C, June HL (2003) D1 dopamine receptor regulates alcohol-motivated behaviors in the bed nucleus of the stria terminalis in alcohol-preferring (P) rats. Synapse 48:45-56.

Epping-Jordan MP, Markou A, Koob GF (1998) The dopamine D-1 receptor antagonist SCH 23390 injected into the dorsolateral bed nucleus of the stria terminalis decreased cocaine reinforcement in the rat. Brain Res 784:105-115.

Erb S, Salmaso N, Rodaros D, Stewart J (2001) A role for the CRFcontaining pathway from central nucleus of the amygdala to bed nucleus of the stria terminalis in the stress-induced reinstatement of cocaine seeking in rats. Psychopharmacology (Berl) 158:360-365.

Faber DS, Korn H (1991) Applicability of the coefficient of variation method for analyzing synaptic plasticity. Biophys J 60:1288-1294.

Freedman LJ, Cassell MD (1994) Distribution of dopaminergic fibers in the central division of the extended amygdala of the rat. Brain Res 633:243-252.

Gerfen CR, Miyachi S, Paletzki R, Brown P (2002) D1 dopamine receptor supersensitivity in the dopamine-depleted striatum results from a switch in the regulation of ERK1/2/MAP kinase. J Neurosci 22:5042-5054.

Guiard BP, El Mansari M, Blier P (2008) Cross-talk between dopaminergic and noradrenergic systems in the rat ventral tegmental area, locus ceruleus, and dorsal hippocampus. Mol Pharmacol 74:1463-1475.

Gustafson EL, Greengard P (1990) Localization of DARPP-32 immunoreactive neurons in the bed nucleus of the stria terminalis and central nucleus of the amygdala: co-distribution with axons containing tyrosine hydroxylase, vasoactive intestinal polypeptide, and calcitonin generelated peptide. Exp Brain Res 79:447-458.

Hasue RH, Shammah-Lagnado SJ (2002) Origin of the dopaminergic innervation of the central extended amygdala and accumbens shell: a combined retrograde tracing and immunohistochemical study in the rat. J Comp Neurol 454:15-33.

Higashi H, Inanaga K, Nishi S, Uchimura N (1989) Enhancement of dopamine actions on rat nucleus accumbens neurones in vitro after methamphetamine pre-treatment. J Physiol 408:587-603.

Hyytiä P, Koob GF (1995) GABAA receptor antagonism in the extended 
amygdala decreases ethanol self-administration in rats. Eur J Pharmacol 283:151-159.

Johnson PM, Kenny PJ (2010) Dopamine D2 receptors in addiction-like reward dysfunction and compulsive eating in obese rats. Nat Neurosci 13:635-641.

Ju G, Swanson LW, Simerly RB (1989) Studies on the cellular architecture of the bed nuclei of the stria terminalis in the rat: II. Chemoarchitecture. J Comp Neurol 280:603-621.

Kalant H (2010) What neurobiology cannot tell us about addiction. Addiction 105:780-789.

Krawczyk M, Georges F, Sharma R, Mason X, Berthet A, Bézard E, Dumont EC (2011) Double-dissociation of the catecholaminergic modulation of synaptic transmission in the oval bed nucleus of the stria terminalis. J Neurophysiol 105:145-153.

Leri F, Flores J, Rodaros D, Stewart J (2002) Blockade of stress-induced but not cocaine-induced reinstatement by infusion of noradrenergic antagonists into the bed nucleus of the stria terminalis or the central nucleus of the amygdala. J Neurosci 22:5713-5718.

Li BH, Rowland NE (1995) Effects of vagotomy on cholecystokinin- and dexfenfluramine-induced Fos-like immunoreactivity in the rat brain. Brain Res Bull 37:589-593.

Li BH, Spector AC, Rowland NE (1994) Reversal of dexfenfluramineinduced anorexia and c-Fos/c-Jun expression by lesion in the lateral parabrachial nucleus. Brain Res 640:255-267.

Li Y, Kauer JA (2004) Repeated exposure to amphetamine disrupts dopaminergic modulation of excitatory synaptic plasticity and neurotransmission in nucleus accumbens. Synapse 51:1-10.

Martin M, Chen BT, Hopf FW, Bowers MS, Bonci A (2006) Cocaine selfadministration selectively abolishes LTD in the core of the nucleus accumbens. Nat Neurosci 9:868-869.

Meloni EG, Gerety LP, Knoll AT, Cohen BM, Carlezon WA Jr (2006) Behavioral and anatomical interactions between dopamine and corticotropinreleasing factor in the rat. J Neurosci 26:3855-3863.

Moga MM, Saper CB, Gray TS (1989) Bed nucleus of the stria terminalis: cytoarchitecture, immunohistochemistry, and projection to the parabrachial nucleus in the rat. J Comp Neurol 283:315-332.

Moore RJ, Vinsant SL, Nader MA, Porrino LJ, Friedman DP (1998) Effect of cocaine self-administration on dopamine D2 receptors in rhesus monkeys. Synapse 30:88-96.

Morgan D, Grant KA, Gage HD, Mach RH, Kaplan JR, Prioleau O, Nader SH, Buchheimer N, Ehrenkaufer RL, Nader MA (2002) Social dominance in monkeys: dopamine D2 receptors and cocaine self-administration. Nat Neurosci 5:169-174.

Nader MA, Daunais JB, Moore T, Nader SH, Moore RJ, Smith HR, Friedman DP, Porrino LJ (2002) Effects of cocaine self-administration on striatal dopamine systems in rhesus monkeys: initial and chronic exposure. Neuropsychopharmacology 27:35-46.

Nader MA, Morgan D, Gage HD, Nader SH, Calhoun TL, Buchheimer N, Ehrenkaufer R, Mach RH (2006) PET imaging of dopamine D2 receptors during chronic cocaine self-administration in monkeys. Nat Neurosci 9:1050-1056.

Namkung Y, Sibley DR (2004) Protein kinase C mediates phosphorylation, desensitization, and trafficking of the D2 dopamine receptor. J Biol Chem 279:49533-49541.

Namkung Y, Dipace C, Urizar E, Javitch JA, Sibley DR (2009) G proteincoupled receptor kinase-2 constitutively regulates D2 dopamine receptor expression and signaling independently of receptor phosphorylation. J Biol Chem 284:34103-34115.
Nann-Vernotica E, Donny EC, Bigelow GE, Walsh SL (2001) Repeated administration of the D1/5 antagonist ecopipam fails to attenuate the subjective effects of cocaine. Psychopharmacology (Berl) 155:338-347.

Nicola SM, Surmeier J, Malenka RC (2000) Dopaminergic modulation of neuronal excitability in the striatum and nucleus accumbens. Annu Rev Neurosci 23:185-215

Panlilio LV (2010) Stimulant self-administration. In: Animal models of drug addiction (Olmstead MC, ed), pp 57-81. New York: Springer.

Paxinos G, Watson C (2005) The rat brain in stereotaxic coordinates, Ed 5. San Diego: Academic.

Pei L, Lee FJ, Moszczynska A, Vukusic B, Liu F (2004) Regulation of dopamine $\mathrm{D} 1$ receptor function by physical interaction with the NMDA receptors. J Neurosci 24:1149-1158.

Phelix CF, Liposits Z, Paull WK (1992) Monoamine innervation of bed nucleus of stria terminalis: an electron microscopic investigation. Brain Res Bull 28:949-965.

Richardson NR, Roberts DC (1996) Progressive ratio schedules in drug selfadministration studies in rats: a method to evaluate reinforcing efficacy. J Neurosci Methods 66:1-11.

Rowland NE, Bellinger LL, Li BH, Mendel VE (1996) Satietin: Fos mapping of putative brain sites of action. Brain Res 717:189-192.

Schalling M, Djurfeldt M, Hökfelt T, Ehrlich M, Kurihara T, Greengard P (1990) Distribution and cellular localization of DARPP-32 mRNA in rat brain. Brain Res Mol Brain Res 7:139-149.

Scibilia RJ, Lachowicz JE, Kilts CD (1992) Topographic nonoverlapping distribution of D1 and D2 dopamine receptors in the amygdaloid nuclear complex of the rat brain. Synapse 11:146-154.

Swanson LS (2003) Brain maps: structure of the rat brain. San Diego: Academic.

Vanderschuren LJ, Everitt BJ (2004) Drug seeking becomes compulsive after prolonged cocaine self-administration. Science 305:1017-1019.

Veinante P, Stoeckel ME, Freund-Mercier MJ (1997) GABA- and peptideimmunoreactivities co-localize in the rat central extended amygdala. Neuroreport 8:2985-2989.

Volkow ND, Fowler IS, Wolf AP, Schlyer D, Shiue CY, Alpert R, Dewey SL, Logan J, Bendriem B, Christman D (1990) Effects of chronic cocaine abuse on postsynaptic dopamine receptors. Am J Psychiatry 147:719-724.

Volkow ND, Fowler JS, Wang GJ, Hitzemann R, Logan J, Schlyer DJ, Dewey SL, Wolf AP (1993) Decreased dopamine D2 receptor availability is associated with reduced frontal metabolism in cocaine abusers. Synapse 14:169-177.

Walker JR, Ahmed SH, Gracy KN, Koob GF (2000) Microinjections of an opiate receptor antagonist into the bed nucleus of the stria terminalis suppress heroin self-administration in dependent rats. Brain Res 854:85-92.

Wise RA (1996) Neurobiology of addiction. Curr Opin Neurobiol 6:243-251.

You ZB, Wang B, Zitzman D, Wise RA (2008) Acetylcholine release in the mesocorticolimbic dopamine system during cocaine seeking: conditioned and unconditioned contributions to reward and motivation. J Neurosci 28:9021-9029.

Zhang W, Ordway GA (2003) The alpha2C-adrenoceptor modulates GABA release in mouse striatum. Brain Res Mol Brain Res 112:24-32.

Zhang W, Klimek V, Farley JT, Zhu MY, Ordway GA (1999) alpha2C adrenoceptors inhibit adenylyl cyclase in mouse striatum: potential activation by dopamine. J Pharmacol Exp Ther 289:1286-1292.

Zucker RS (1989) Short-term synaptic plasticity. Annu Rev Neurosci 12: $13-31$. 